\title{
SWAPDT: A method for Short-time Withering Assessment of Probability for Drought Tolerance in Camellia sinensis validated by targeted metabolomics
}

\author{
Christopher Nyarukowa ${ }^{1}$, Robert Koech ${ }^{1,2}$, Theodor Loots ${ }^{3}$, Zeno Apostolides ${ }^{1 *}$ \\ ${ }^{1}$ Department of Biochemistry, University of Pretoria, Private Bag X20, Hatfield, 0028, South Africa. \\ ${ }^{2}$ Tea Research Institute (TRI), P.O Box 820-20200, Kericho, Kenya \\ ${ }^{3}$ Department of Statistics, University of Pretoria, Private Bag X20, Hatfield, 0028, South Africa. \\ * Address correspondence to:
}

Prof. Zeno Apostolides, Department of Biochemistry, University of Pretoria, Private Bag X20, Hatfield, 0028, South Africa. Email: zeno.apostolides@up.ac.za. Phone: +27(0)12 420-2486. Fax: +27(0)12 3625302
Abbreviations
- DS
Drought susceptible
- DT
Drought tolerant
- $\mathrm{GC}$
Gas chromatography
- LC
Liquid chromatography
- PCA
Principal component analysis
- P5CS
Pyrroline-5-caboxylate synthetase
- $\mathrm{GR}$
Glutathione reductase
- GSA
Glutamate-semialdehyde
- RWC
Relative water content
- TPC
Total polyphenol content 


\begin{abstract}
Climate change is causing droughts affecting crop production on a global scale. Classical breeding and selection strategies for drought-tolerant cultivars will help prevent crop losses. Plant breeders, for all crops, need a simple and reliable method to identify drought-tolerant cultivars, but such a method is missing. Plant metabolism is often disrupted by abiotic stress conditions. To survive drought, plants reconfigure their metabolic pathways. Studies have documented the importance of metabolic regulation, i.e. osmolyte accumulation such as polyols and sugars (mannitol, sorbitol); amino acids (proline) during drought. This study identified and quantified metabolites in drought tolerant and drought susceptible Camellia sinensis cultivars under wet and drought stress conditions. For analyses, GC-MS and LC-MS were employed for metabolomics analysis. \%RWC results show how the two drought tolerant and two drought susceptible cultivars differed significantly $(\mathrm{p} \leq 0.05)$ from one another; the drought susceptible exhibited rapid water loss compared to the drought tolerant. There was a significant variation $(\mathrm{p}<0.05)$ in metabolite content (amino acid, sugars) between drought tolerant and drought susceptible tea cultivars after short-time withering conditions. These metabolite changes were similar to those seen in other plant species under drought conditions, thus validating this method. The Short-time Withering Assessment of Probability for Drought Tolerance (SWAPDT) method presented here provides an easy method to identify drought tolerant tea cultivars that will mitigate the effects of drought due to climate change on crop losses.
\end{abstract}

\title{
Keywords
}

Abiotic stress; amino acids; Camellia sinensis; carbohydrates; drought tolerance; GC-MS; LC-MS; metabolite profiling; short-time withering; targeted metabolomics.

\section{Introduction}

\section{Camellia sinensis}

Tea made from the leaves of Camellia sinensis, as green or black tea, has been drunk as a mild stimulant due to the caffeine content, since time immemorial! Tea consumption has been increasing in recent years, due to the health promoting effects associated with its rich polyphenol content (Tong et al., 2014). Plant response to stress is manifested by physiological and metabolomic responses (Maritim et al., 2015). This enables the screening and selection of tea cultivars resistant to drought stress, through organic osmolytes 
accumulation. Most osmolytes are secondary metabolites, and tea contains high polyphenol amounts (Cheruiyot et al., 2007). No metabolites have been investigated in C. sinensis in relation to drought. However, several metabolites have been documented in literature relative to drought stress in other plant species. This study focuses on polyphenols, flavonoids, amino acids and sugars.

\section{Plant metabolomics}

When plants are subjected to abiotic stress conditions, metabolic enzyme inhibition or substrate shortage, etc. disrupts plant metabolism resulting in metabolic pathway reconfiguration, ensuring plant survival (Hamanishi et al., 2015). Plants have established innumerable strategies in response to drought (Ogbaga et al., 2014). A common leaf response to drought stress involves both physical and morphological changes. Studies on leaves in connection with drought tolerance have been documented in different plants but not in Camellia sinensis. Several studies have been conducted on plants subjected to drought stress, showing the importance of metabolic regulation, i.e. accumulation of osmolytes in a response to drought stress (Slama et al., 2015). Hyperosmotic stress produces osmolytes which include polyols and sugars (mannitol, sorbitol and trehalose) and amino acids (proline and betaine) (Weckwerth et al., 2004). These compounds are water soluble and non-toxic at high concentrations. They stabilise protein structure while decreasing protein-solvent interactions during water deficit, repair damaged tissues and support growth (Ruan and Teixeira da Silva, 2011). Metabolomic changes in Arabidopsis leaves under drought conditions show that proline, raffinose, $\gamma$-amino butyrate (GABA) and Krebs cycle intermediates accumulate in response to drought stress (Urano et al., 2009). Proline accumulation is integral for a cell's adaptation to hyperosmotic stress. It decreases water potential resulting in osmotic adjustment and maintaining of cell turgor. A large number of plant species accumulate proline in response to osmotic stress. Proline biosynthesis is activated under dehydration conditions with pyrroline-5-caboxylate synthetase (P5CS) as the target enzyme. Alternative pathways responsible for proline upregulation under drought stress include the pentose phosphate pathway. Proline biosynthesis also regulates cytosolic $\mathrm{pH}$ and $\mathrm{NADP}^{+}$synthesis, which are key in stimulating the pentose phosphate pathway (Hare and Cress, 1997).

Glucose and fructose levels increase in apple trees subjected to drought conditions while starch levels decrease (Ayaz et al., 2000). This suggests that both sugar alcohols and monosaccharaides play a key role in osmotic adjustment (Pandey et al., 2004). The decrease in starch concentration can be attributed to the fact that drought stress reduces the rate of 
photosynthesis. Carbohydrate metabolism is linked to photosynthesis, making it pivotal in the stress tolerance. Monosaccharaides such as glucose and fructose represent 38\% (w/w) and sucrose $62 \%(\mathrm{w} / \mathrm{w})$ of the total soluble sugars (daily average) found in watered plants, and 53\% (w/w) and 47\% (w/w) respectively in drought subjected plants (Rodrigues et al., 1993). As drought exposure prolongs, a reduction in the abundance of the two sugars occurs because they are increasingly being converted into protective sugars (Farrant et al., 2009).

\section{Current drought tolerance assessment}

Recurring droughts and future climate change necessitate the selection of DT tea cultivars for a sustainable tea industry. The current method for drought tolerance assessment in Camellia sinensis is visual assessment of leaf wilting and scoring on a five-point scale. This is done under field conditions, during natural droughts that occur every 3-7 years. This method is subjective and poorly reproducible due to environmental conditions. An accurate and reproducible method is required to help tea breeders classify new cultivars as DT or DS. The new method should be independent of natural droughts and subjective evaluations. This inspired us to develop a short-time withering method and objective measurement of RWC, as a surrogate marker for calculating the probability of drought tolerance of new tea cultivars. This method is based on leaf RWC by mass balance as described below. The modulation of leaf metabolites (amino acids, sugars and flavonoids) between wet and drought conditions, have been determined in various plant species (as described above), but never in tea. Thus, modulation of tea leaf metabolites will be measured to validate the new method. We anticipate that the metabolite changes found in other plant species, under prolonged drought conditions, will occur in plucked tea shoots during the new short-time withering method. The main focus throughout this study was to identify, quantify and validate the metabolites in DT and DS tea (C. sinensis) cultivars affected by drought stress using the Short-time Withering Assessment of Probability for Drought Tolerance (SWAPDT) method.

\section{Materials and methods}

Five biological replicates from each of the two drought tolerant cultivars (PC168 and PC153) and five biological repeats each from the two drought susceptible cultivars (PC105 and PC165) developed at the Tea Research Foundation for Central Africa in Malawi grown in pots under shade net at the University of Pretoria experimental farm in Hatfield, Pretoria and four DT cultivars (SFS 150, TN 14-3, 301/4 and 303/577) and four DS cultivars (AHP S15/10, TRFK 371/8, SC12/28 and Ejulu) grown at the Tea Research Institute in Kenya were used in this study. 


\section{Polyphenol extraction and content determination}

Before extractions, fresh leaves from each cultivar growing under a shade net were microwave dried for five min, which in the process deactivated the oxidizing enzyme polyphenol oxidase. A coffee grinder was used to grind the dried leaves and sieved through a $355 \mu \mathrm{m}$ stainless-steel sieve and stored at $4{ }^{\circ} \mathrm{C}$ in plastic zip-lock bags prior to extracting polyphenols. International Organization for Standardization (ISO) extraction method was used as is described in the ISO document 14502-1: 2005. Briefly, $0.200 \pm 0.001 \mathrm{~g}$ of each sample was weighed out on a Mettler Toledo analytical balance (Microcep, South Africa) and transferred into a glass extraction tube. A five ml volume of 70:30 methanol (Merck, South Africa): water (v/v) at $70{ }^{\circ} \mathrm{C}$ was added to each extraction tube, stoppered and vortex mixed for approximately five seconds before placing into a water bath set at $70^{\circ} \mathrm{C}$. The deionized water $\left(\mathrm{H}_{2} \mathrm{O}\right)$ was purified by a purification system from ELGA PURELAB Ultra, Labotec. The extraction mixture was vortex mixed after five min and again at ten min when tubes were removed from water bath. After cooling at room temperature with the stopper off for an additional five min, the extracts were centrifuged at $2000 \mathrm{Xg}$ for ten min, with the resultant supernatant decanted into a ten $\mathrm{ml}$ measuring cylinder. The extraction step was repeated twice. Both extracts were pooled, and the volume adjusted to ten ml with cold 70:30 methanol: water $(\mathrm{v} / \mathrm{v})$.

A volume of one $\mathrm{ml}$ of the extract was diluted with water to $100 \mathrm{ml}$. The total polyphenol content (TPC) was determined according to ISO 14502-1: 2005 procedure, with Gallic acid (Sigma-Aldrich, South Africa) as standard. From the 1/100 ml extract sample dilution, a one $\mathrm{ml}$ volume was transferred in duplicate into separate glass tubes. Five $\mathrm{ml}$ of a 1/10 dilution of Folin-Ciocalteu reagent (Merck Chemicals, South Africa) in water was pipetted into each tube and mixed. After five min, four $\mathrm{ml}$ of anhydrous sodium carbonate (Sigma-Aldrich, South Africa) solution $(7.5 \% \mathrm{w} / \mathrm{v})$ was added to each tube, stoppered and mixed before being allowed to stand at room temperature for $60 \mathrm{~min}$. The absorbance was measured at $765 \mathrm{~nm}$ on a Thermo Multiskan Ascent microplate reader against water. Gallic acid standards were used for quantification and the results were expressed as \% Gallic acid equivalents (GAE) in g/100 g dry weight plant material. The Gallic acid standard curve which was linear from 10 to 50 $\mu \mathrm{g} / \mathrm{ml}$ in the assay was used to measure the polyphenol content in each of the samples. TPC, expressed as a \% (w/w) by mass on a sample dry matter basis, is given by the formula: 


$$
\% \mathrm{TPC}=\left(\mathrm{OD}_{\text {sample }} \underline{\left.-\mathrm{OD}_{\text {intercept }}\right) \times \mathrm{V} \text { X d x } 100}\right.
$$

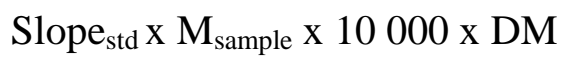

where $\mathrm{OD}_{\text {sample }}$ is optical density obtained for the sample, $\mathrm{OD}_{\text {intercept }}$ is optical density at the

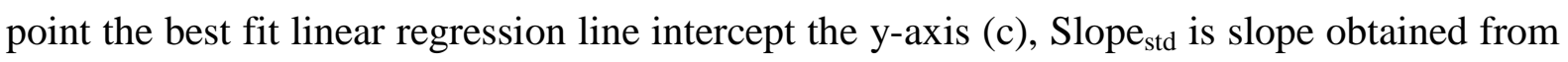
best fit linear regression (m), $\mathbf{M}_{\text {sample }}$ is mass of sample $(\mathrm{mg}), \mathrm{V}$ is extraction volume $(\mathrm{ml}), \mathrm{d}$ is dilution factor used prior to the colorimetric determination (one $\mathrm{ml}$ to $100 \mathrm{ml}=100 \mathrm{X}$ ), DM is the dry matter content expressed as a mass fraction of test sample and 10000 is a dilution factor.

\section{The SWAPDT method}

The rate of RWC loss between the DT and DS cultivars was evaluated as described by Yobi et al., (2012) in a comparative metabolic profiling study between DT and DS Selaginella species. Three shoots with two leaves and a bud from a single bush of each of the cultivars were immersed in $20 \mathrm{ml}$ of distilled water at room temperature and weighed hourly for five hours until the leaves reached constant weight. The hydrated (turgid) leaves were then removed from respective solutions, blot dried to remove surface water and weighed $(t=0)$. After the initial weighing, the leaves were oven dried at $37^{\circ} \mathrm{C}$ and weighed at $60 \mathrm{~min}$ intervals for five hours, until their RWC was approximately 50\% (based on prior explorative experiments). The leaves were again placed in water, with the leaves above water and petiole in the water (Figure 1), and left for 24 hours with the weights noted hourly for the first five

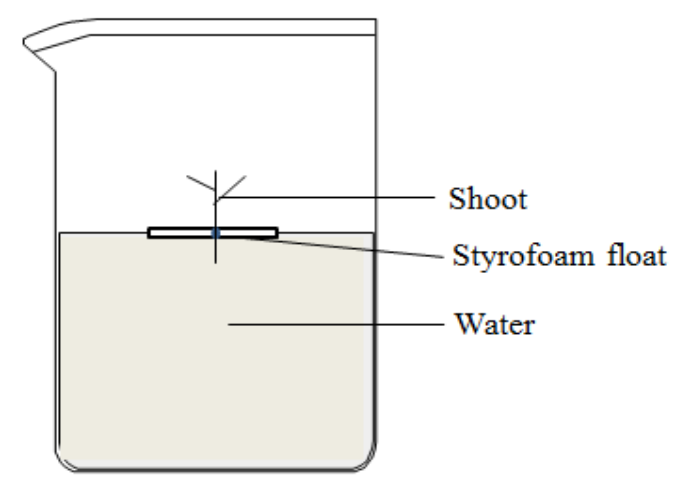

Figure 1: Shows the placement of the shoot in water; the petiole is submerged in distilled water.

hours. The leaves were weighed after 24 hours and oven dried at $105^{\circ} \mathrm{C}$ for 24 hours to obtain each leaf's dry weight. The \% RWC $0 . . .5$ hours was then calculated using the formula:

$$
\% \text { RWC } 0 . . .5=\left(\mathrm{F}_{\mathrm{wt}}-\mathrm{D}_{\mathrm{wt}}\right) /\left(\mathrm{FT}_{\mathrm{wt}}-\mathrm{D}_{\mathrm{wt}}\right) * 100
$$


where $\mathrm{F}_{\mathrm{wt}} 0 \ldots 5$ is the hourly weight while drying at $37^{\circ} \mathrm{C}$ for five hours, $\mathrm{D}_{\mathrm{wt}}$ is the dry weight after 24 hours in $105^{\circ} \mathrm{C}$ oven and $\mathrm{FT}_{\mathrm{wt}}$ is the weight after 24 hour rehydration. The final \% RWC was normalised with respect to the first value, making all values relative to $t=0$. The $\%$ RWCs at $\mathrm{t}=0$ and $\mathrm{t}=5$ were chosen for the comparative metabolite composition study between the two types of cultivars. Figure 2 shows a diagrammatic representation of the experimental procedure.

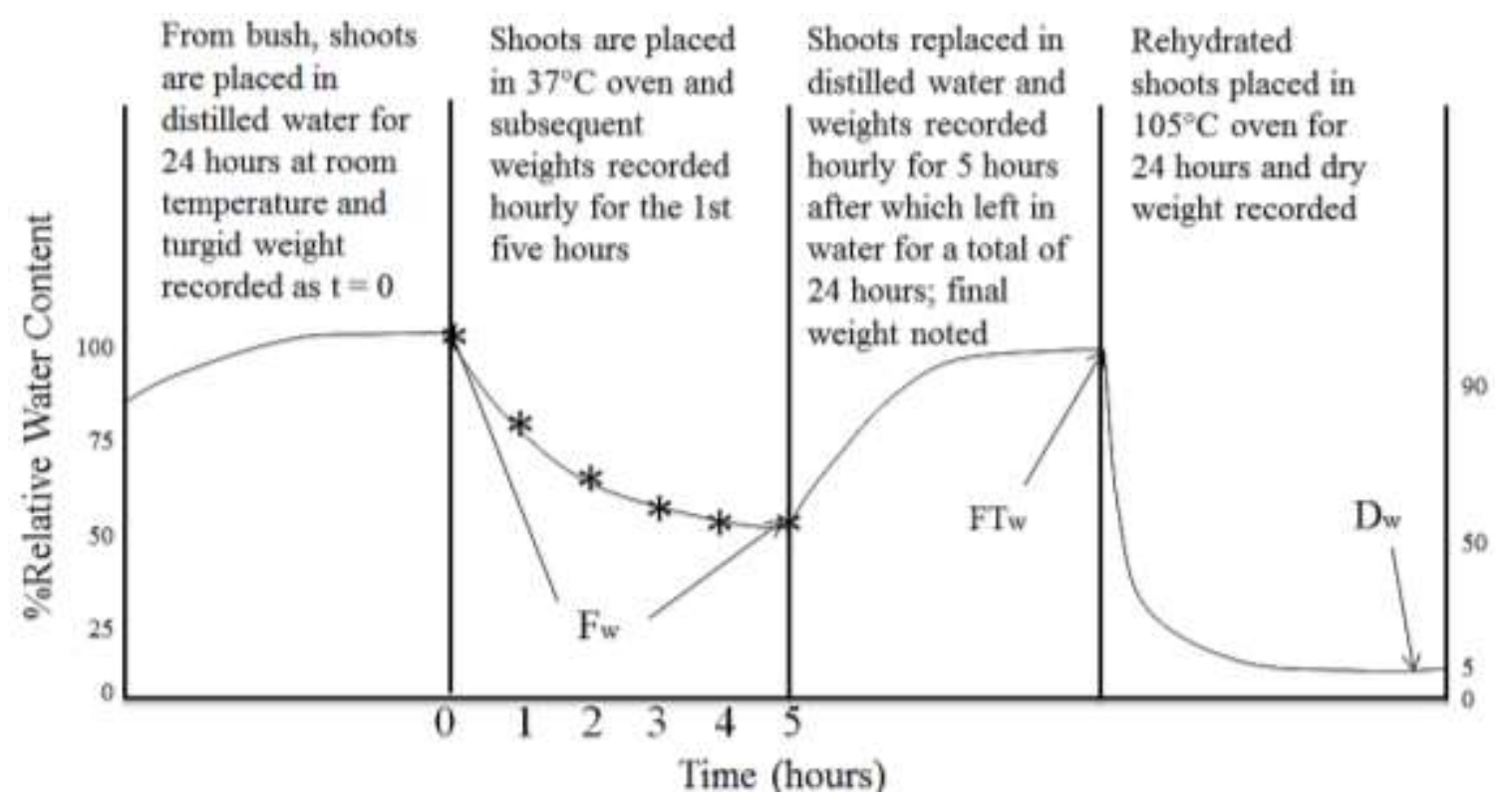

Figure 2: Diagrammatic representation of the experimental procedure.

\section{Chromatography}

Two working stock solutions were prepared. One consisted of amino acids (valine, leucine, isoleucine, glycine, glutamic acid, aspartic acid, asparagine, phenylalanine, proline and lysine) (Sigma-Aldrich, South Africa) and the carbohydrates (glucose, fructose, mannitol and citrate) (Sigma-Aldrich, South Africa) standards dissolved in 50:50 methanol: water (v/v) at one $\mathrm{mg} / \mathrm{ml}$. The second cocktail consisted of phenolic compounds (trans-cinnamic acid, vanillic acid, coumaric acid, gallic acid, caffeic acid and protocatechuic acid) (SigmaAldrich, South Africa) at one $\mathrm{mg} / \mathrm{ml}$ in 50:50 methanol: water (v/v). These functioned as internal standards for both GC-MS and LC-MS analysis. An injection volume of one $\mu 1$ was used to give a standard final concentration of one $\mu \mathrm{g} / \mathrm{injection}$. The standard solutions were filtered through a $0.2 \mu \mathrm{m}$ Minisart ${ }^{\circledR}$ RC4 syringe filters (Sartorious) with hydrophilic, solvent-resistant regenerated cellulose membranes prior to injection. All extracts, stock and internal standard solutions were stored at $4^{\circ} \mathrm{C}$. 


\section{Targeted metabolomics}

\section{GC-MS sample preparation and analysis}

Fresh tea leaves were picked from the 20 individual tea plants at 06h00, placed in labelled plastic bags and kept on ice. These samples were couriered overnight to the Central Analytical Facility of the University of Stellenbosch were the GC-MS and LC-MS analysis were done as described below.

The fresh leaves were ground to a fine powder in liquid nitrogen. The powder samples were then weighed and extracted with one ml 70:30 methanol: water (v/v). After extraction, $100 \mu 1$ of ribitol was added as an internal standard after which the samples were kept overnight at $70^{\circ} \mathrm{C}$. The overnight mixture was allowed to cool before centrifugation at $17000 \mathrm{~g}$ for five min. Two hundred microliters of the extracts was transferred into a clean Eppendorf tube and dried on a Savant DNA 110 Speed vac. The concentrator of the speed vac setting was switched on with the drying rate set at low. The low drying rate was used to preserve the metabolites, preventing amino acids break down. The dried extracts were reconstituted in $100 \mu \mathrm{l}(2.5 \%)$ methoxyamine hydrochloride in 50:50 pyridine: acetonitrile (Merck, South Africa) (v/v) and left for two hours at $40^{\circ} \mathrm{C}$. Fifty $\mu 1$ of BSTFA with $1 \%$ TMCS was added and the mixture derivatised at $60^{\circ} \mathrm{C}$ for $30 \mathrm{~min}$. The samples were then cooled and vortexed for a few seconds before being transferred into a GC vial with an insert. A Trace 1300 coupled to a Thermo TSQ 8000 GC-MS/MS (Thermo scientific) with a TriLusRSH autosampler and a non-polar (95\% dimethylpolysiloxane) capillary column Restek -Rxi @-5Sil MS w/Intrega-Guard ® (15 m, $0.25 \mathrm{~mm} \mathrm{ID,} 0.25 \mu \mathrm{m}$ film thickness) was used for targeted metabolite profiling. The initial oven temperature was maintained at $100^{\circ} \mathrm{C}$ for four min, and then ramped at $6^{\circ} \mathrm{C} / \mathrm{min}$ to $180^{\circ} \mathrm{C}$, held for two min and ramped at $15^{\circ} \mathrm{C} / \mathrm{min}$ to $300^{\circ} \mathrm{C}$ and then held for five min. Helium was used as the carrier gas at a flow rate of one $\mathrm{ml} / \mathrm{min}$ with the injector temperature maintained at $280^{\circ} \mathrm{C}$, operated in a split less mode. The mass spectral data was recorded on a TSQ operated in a single ion monitoring (SIM) mode. Both the ion source and transfer line temperatures were set at $240^{\circ} \mathrm{C}$.

\section{LC-MS analysis}

The samples were ground to a fine powder and extracted as described for the GC analyses. An injection volume of three $\mu$ l was used. A Waters Synapt G2 quadrupole time-of-flight mass spectrometer fitted with a Waters Acquity UPLC and photo-diode array detector (PDA), was used for LC-MS analysis. Separation was achieved on a Waters Acquity HSS T3 column $(1.8 \mu \mathrm{m}, 2.1 \times 150 \mathrm{~mm})$. Solvent A consisted of water with $0.1 \%$ formic acid while solvent B was made up of $0.1 \%$ formic acid in acetonitrile. The gradient employed consisted of a flow 
rate $0.32 \mathrm{ml} / \mathrm{min}$, starting with $0 \% \mathrm{~B}$ to $5.0 \% \mathrm{~B}$ over four min, then to $40 \% \mathrm{~B}$ over $11 \mathrm{~min}$, followed by a linear gradient to $100 \% \mathrm{~B}$ over the next one min and kept constant for one min during column wash in $100 \% \mathrm{~B}$. This was followed by re-equilibration to initial conditions over three min for a total runtime of 20 minutes. Electrospray ionisation was applied in the positive mode, with a capillary voltage of $2.5 \mathrm{kV}$, a cone voltage of $15 \mathrm{~V}$, desolvation temperature of $275^{\circ} \mathrm{C}$ and desolvation gas $\left(\mathrm{N}_{2}\right)$ flow of $650 \mathrm{~L} \cdot \mathrm{h}^{-1}$. The source temperature was set to $120^{\circ} \mathrm{C}$. The rest of the MS settings were optimised for best sensitivity. Data was acquired in MSE mode, consisting of a scan using low collision energy of $6 \mathrm{eV}$ and a scan using a collision energy ramp from 25 to $60 \mathrm{~V}$. Sodium formate was used to calibrate the instrument and leucine encephalin was used for the lock spray for accurate mass determination. The PDA detector was set to scan over the range 230-700 nm. The raw LCMS data was obtained from the CAF on an external drive.

\section{Data Processing and Statistical Analysis}

All the data from the samples was 0 normalised and 1 standardised to minimise systematic variation within the data, before multivariate analysis. Data acquisition and processing was conducted using MassLynx 4.1 software. The raw data obtained from LC-MS was converted into Network Common Data Form (NetCDF) format using the Databridge software application manager from Waters Corp, Milford, MA. GC-MS results were analysed directly. SIMCA-P 14.0 (Umea, Sweden) and JMP pro 12 software were used to conduct multivariate statistical analysis to identify key metabolites. JMP Pro 12 was used to perform one way analysis of variance (ANOVA). Both the Student's t-test, with the alpha level set to 0.05 and ANOVA were conducted to determine the significance of the up or down regulation of each metabolite. High-dimensional and complex data sets are generated whenever metabolomic studies are conducted. The analysis and interpretation of such data sets proves impossible just by visual inspection or univariate statistical analysis. As a result, multivariate statistical data analysis mathematical modelling approaches, namely PCA (Figure 5) was employed to enable accurate extraction and interpretation of large empirical data sets. Logistic regression models were developed for classifying $C$. sinensis cultivars into DT and DS categories, based on specific metabolites. The data was transformed to adjust for leaf weight and moisture content at five hours, after which a stepwise logistic regression was done. Two models were developed at $\mathrm{t}=0$ and $\mathrm{t}=5$ for different variables/metabolites (Table 1 and 2). Due to the small number (20) metabolites, it was decided to use the two-variable model with the variables appearing frequently in other higher order models at the $\mathrm{t}=0$ and $\mathrm{t}=5$ levels. 
Table 1: Logistic regression model at $\mathrm{t}=0$ as a single model.

\begin{tabular}{|c|c|c|}
\hline \multicolumn{3}{|c|}{ Regression Models Selected by Score Criterion at $t=0$} \\
\hline Number of Variables & Score Chi-Square & Variables Included in Model \\
\hline 1 & 8.9934 & Glu \\
\hline 1 & 5.8461 & Val \\
\hline 1 & 5.0152 & Leu \\
\hline 2 & 12.4037 & Val Glut \\
\hline 2 & 11.8386 & Leu Glut \\
\hline 2 & 10.9995 & Val Man \\
\hline 3 & 15.2223 & Val Glut Man \\
\hline 3 & 14.9354 & Leu Glut Man \\
\hline 3 & 14.7392 & Val Glut Glu \\
\hline 4 & 16.3191 & Leu Glyc Glut Glu \\
\hline 4 & 16.2382 & Val Glut Prot Glu \\
\hline 4 & 16.2245 & Leu Glut Prot Glu \\
\hline
\end{tabular}

Table 2: Logistic regression models at $\mathrm{t}=5$ as a single model.

\begin{tabular}{|c|c|c|}
\hline \multicolumn{3}{|c|}{ Regression Models Selected by Score Criterion at $t=5$} \\
\hline Number of Variables & Score Chi-Square & Variables Included in Model \\
\hline 1 & 6.0708 & Gal \\
\hline 1 & 4.9392 & Asp \\
\hline 1 & 4.4514 & Prot \\
\hline 2 & 11.6893 & $\underline{\text { Val Asp }}$ \\
\hline 2 & 11.0604 & Leu Asp \\
\hline 2 & 10.6539 & Glut Asp \\
\hline 3 & 14.4470 & Val Asp Citric \\
\hline 3 & 13.7405 & Leu Asp Citric \\
\hline 3 & 12.7857 & Val Asp TCin \\
\hline 4 & 15.3486 & Val Asp Asn Van \\
\hline 4 & 15.1651 & Val TCin Asn Prot \\
\hline
\end{tabular}




\begin{tabular}{|l|l|l|}
\hline 4 & 14.8718 & Val Glyc TCin Asn \\
\hline
\end{tabular}

Table 3: Cross-validation results.

\begin{tabular}{|c|c|c|c|}
\hline Model & $\mathrm{t}=0$ & $\mathrm{t}=5$ & Total \\
\hline $\mathrm{t}=5$ & $15 / 18=83 \%$ & $17 / 20=85 \%$ & $32 / 38=84 \%$ \\
\hline $\mathrm{t}=0$ & $15 / 18=83 \%$ & $13 / 20=65 \%$ & $28 / 38=74 \%$ \\
\hline
\end{tabular}

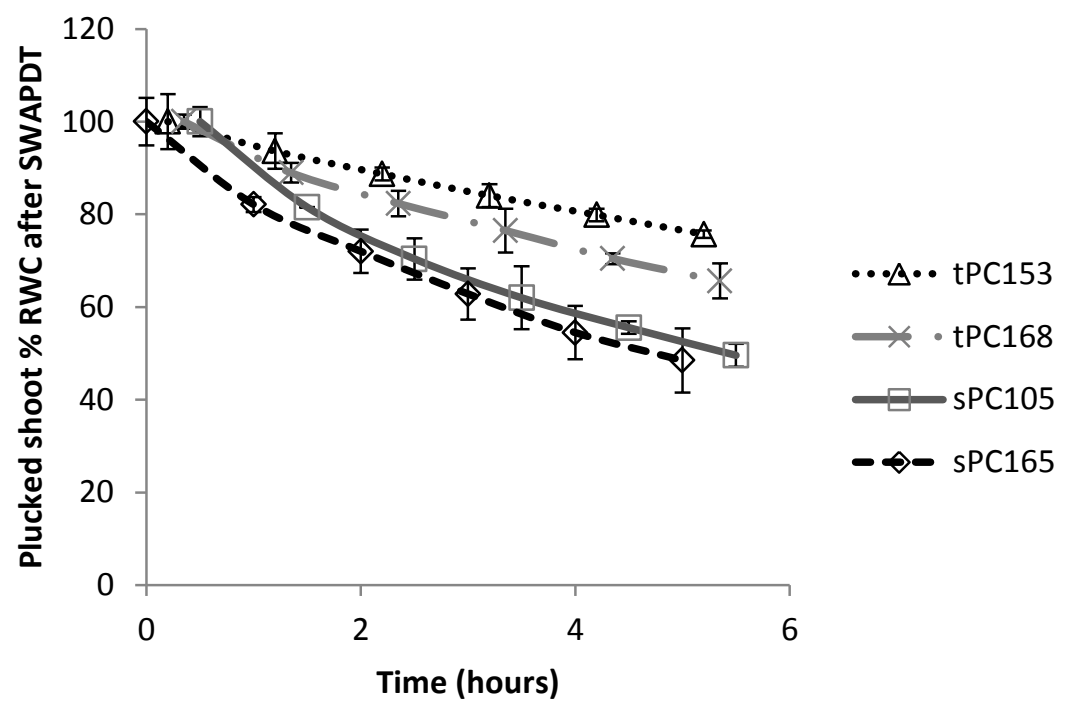

Figure 3: RWC (\%) of $C$. sinensis DT (tPC168 and tPC153) and DS (sPC105 and sPC165) cultivars. The error bars are representative of S.E.M with $n=5$.

\section{Results and Discussion}

\section{Short-term wither method}

Although all the cultivars used i.e. DT (tPC153 and tPC168) and DS (sPC105 and sPC165) share similar ancestral and anatomical properties, they have been classified as DT or DS based on field observations over many years. The dehydration curves of the two DT and two DS cultivars show small differences between cultivars within the same class, they surprisingly show large differences between the classes. The sPC105 and sPC165 exhibited rapid water loss as compared to the DT tPC153 and tPC168 cultivars. SPC165 had a more drastic water loss rate than SPC105. The DT cultivars tPC153 and tPC168 had 75 and 65\% RWC respectively, after five hours, while sPC105 and sPC165 had 50 and 48\% RWC respectively (Figure 4). The \%RWC differed significantly (non-overlapping SEM error bars) 
between DT and DS cultivars, after two hours. The difference continued to increase up to five hours. Even though the results documented in Figure 4 are over five hours of water stress, they are comparable and correlate with the results obtained by Yobi et al., (2012) who conducted similar studies on ferns over 24 hours.

Further work was done to on four DT cultivars (SFS 150, TN 14-3, 301/4 and 303/577) and four DS cultivars (AHP S15/10, TRFK 371/8, SC12/28 and Ejulu) grown at the Tea Research Institute in Kenya to validate the SWAPDT method and those results are shown in figure 4:

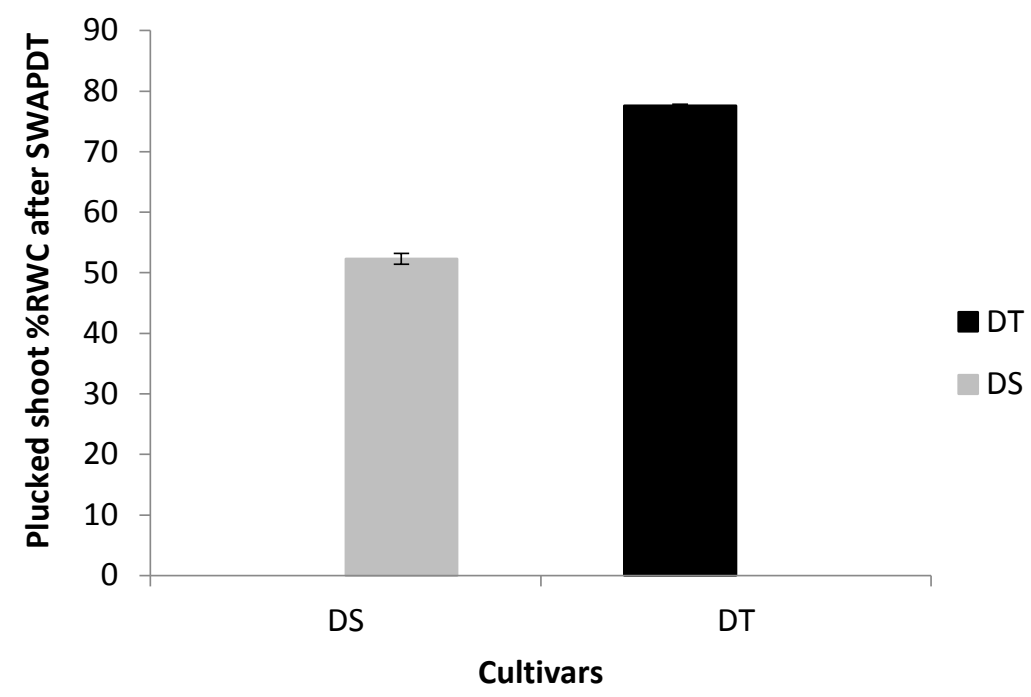

Figure 4: RWC (\%) of plucked tea shoots of $C$. sinensis DS (AHP S15/10, TRFK 371/8, SC12/28 and Ejulu) and DT (SFS 150, TN 14-3, 301/4 and 303/577) after SWAPDT in cultivars classified as DS or DT after many years of field observations. The error bars represent S.E.M with $n=4$.

The metabolomic results confirmed that the changes in amino acids, flavonoids and carbohydrates, during this five-hour wither in tea, are similar to the metabolomic changes found in other plant species, over longer times.

\section{Data Processing and Statistical Analysis}

From the 20 metabolites investigated, a few key metabolites were responsible for causing clustering between the tolerant and the susceptible cultivars. The trend observed (Figure 5) is the same as what has been documented in other plants that have been exposed to drought stress over longer times (Engelbrecht and Kursar, 2003). The cross validation results show that the model developed on the $\mathrm{t}=5$ data works equally well on the $\mathrm{t}=0$ and $\mathrm{t}=5$ data, namely $85 \%$ and $83 \%$ correct classification respectively. However, the model built on the $\mathrm{t}=$ 0 data did not work equally well on the $\mathrm{t}=0$ and $\mathrm{t}=5$ data, namely $65 \%$ and $83 \%$ correct 
classification respectively. This means that targeted metabolomics of fresh leaves $(t=0)$ cannot be used to classify tea cultivars as DT or DS.

For the Model $t=0$;

$p=1 /(1+e-(2192.90674170605$ Val-759.258878377219Glut $)$

For the Model $t=5$;

$p=1 /(1+e-(439.122693812145 \mathrm{Val}-683.855963516112 \mathrm{Asp})$

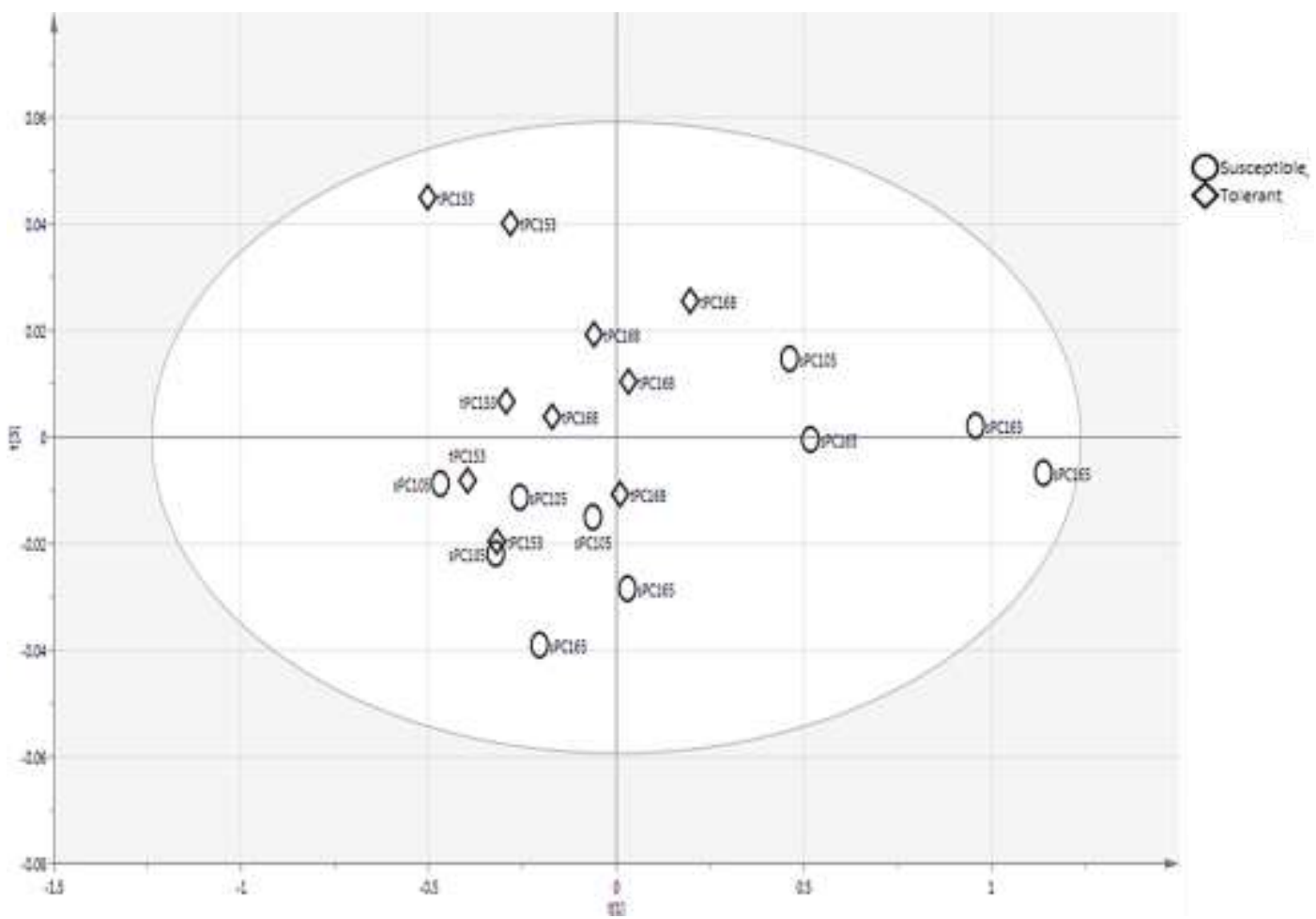

Figure 5: Shows a PCA clustering of $C$. sinensis cultivars at $t=5$, with $n=5$ for each cultivar. SIMCA-P 14 was used to obtain the plot. The diamonds represent samples of the drought tolerant, and the circle of the drought susceptible cultivars.

\section{Targeted metabolomics}

\section{Amino acid metabolism}

The amino acid data obtained from the GC-MS analysis showed that eight amino acids were detected from the 10 that were analysed. Asparagine, glycine, valine, isoleucine, proline and leucine were significantly $(\mathrm{p}<0.05)$ higher in the DT cultivars, after five hours at $37^{\circ} \mathrm{C}$ than in the DS cultivars. Aspartic acid was significantly $(\mathrm{p}<0.004)$ lower in the DT cultivars than the DS cultivars at this time.

The amino acid concentrations in the stressed leaves display an accumulation pattern similar to that found in a study which substantiates their role as osmolytes (Rontein et al., 2002). Drought stress affects plant metabolism, also hindering protein synthesis. The elevated levels 
of amino acids obtained in this study are attributed to a reduction in protein synthesis and an increase in the breakdown of current proteins. In this study, there was an up-regulation of valine, leucine and isoleucine in the DT cultivars as compared to the DS cultivars (Figure 6). This result coincides with results by Arbona et al., (2013) who investigated the accumulation of glucosinolates in Arabidopsis plants subjected to drought stress. The levels of proline in the current study were significantly $(\mathrm{p}<0.04)$ higher in DT as compared to DS cultivars. This is attributed to the P5CS gene, which is highly expressed in tolerant than susceptible

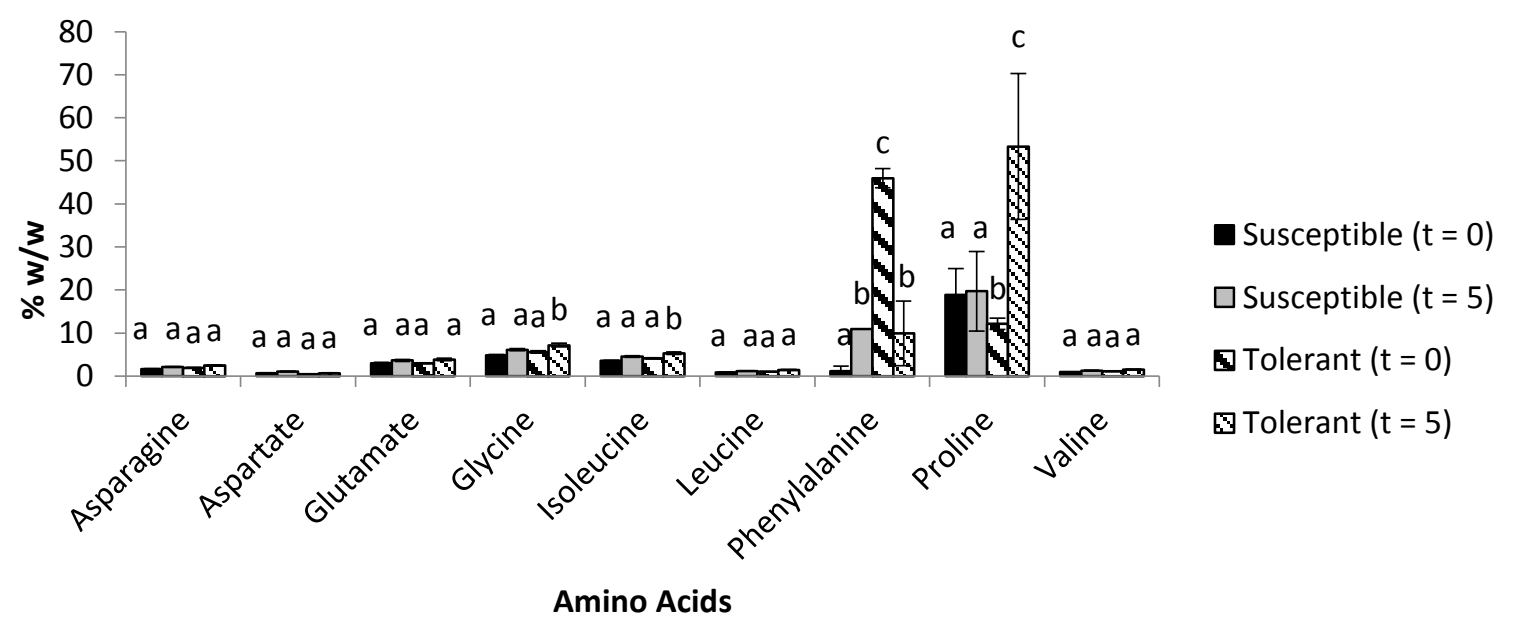

Figure 6: Differences in amino acid abundances between DT and DS at $t=0$ and $t=5$. The means are based on five independent growing plants of two DT or two DS cultivars. Error bars are representative of SEM with $\mathrm{n}=$ 5.

varieties under drought stress resulting in an accumulation of proline in Rapeseed (Janská et al., 2010). The results also showed an increase in the levels of isoleucine in the DT cultivars while aspartic acid levels were lower in the DT. A study on the drought response of Poplar trees found that isoleucine had the highest fold increase in DT Poplar trees as compared to the DS under drought stress (Hamanishi et al., 2015). This is in agreement with the results obtained in this study.

\section{Carbohydrates metabolism}

Carbohydrates are among the most studied metabolites with regards to their accumulation in the vegetative tissues of plants in response to drought stress (Iglesias et al., 2002). Unlike what was observed with the amino acids, remarkable differences were apparent between the DT and DS cultivars. There was a significant down regulation of the carbohydrate metabolites noted in the DT cultivars as compared to the DS cultivars (Figure 7). 
The photosynthetic pathway is the most affected when plants are subjected to abiotic stresses such as drought (Kerchev et al., 2012). This negatively impacts on primary metabolism, affecting metabolites such as sugars, sugar alcohols and amino acids. Most plants use fructose as an energy source when subjected to stress (Kaplan and Guy, 2004). This explains the increase in fructose concentration observed in the DS tea cultivars. The lower fructose levels in the DT cultivars are because DT cultivars utilise fructose at a faster rate than the DS, ensuring their survival under drought stress. Under water deficit glucose concentrations have also been documented to increase in DS plant varieties (Iordachescu and Imai, 2008), which

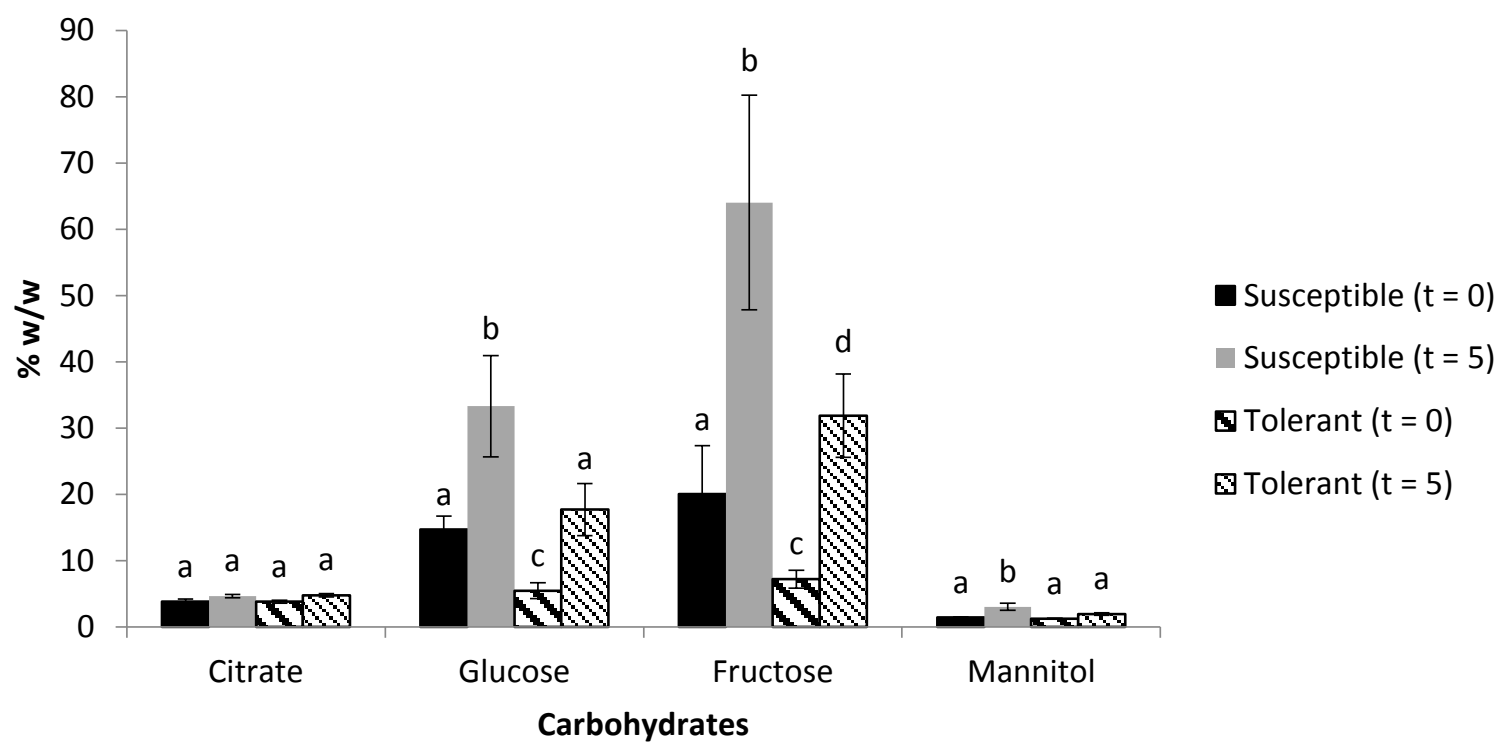

Figure 7: Differences in carbohydrate abundances between DT and DS at $t=0$ and $t=5$. The means are based on five independent growing plants of two DT or two DS cultivars. Error bars are representative of SEM with n $=5$.

is agreement with results obtained in this study. An accumulation of glucose also results in the biosynthesis of trehalose, which is a disaccharide formed by an $\alpha, \alpha-1,1$-glucoside bond between two $\alpha$-glucose residues. Trehalose is a sugar reserve, supplying the plant with energy to cope with stress, as well as a stress protectant. This carbohydrate is also responsible for protein and membrane stabilisation (Yoshida and Sakamoto, 2009). Furthermore, a significant increase in the concentrations of polyols i.e. mannitol was observed. This observation is consistent with results obtained in a study which showed polyols can be synthesised from their analogue sugars under reducing conditions (Pavli et al., 2013). The accumulation pattern observed in this study agrees with the findings by other researchers that polyols function in osmoregulation under drought stress (Rizhsky et al., 2004). Mannitol confers stress tolerance through actively scavenging hydroxyl radicals and is found in lower 
concentrations in DT cultivars than in DS wheat crops (Abebe et al., 2003). Similar results were obtained in the reported study where the levels of mannitol were lower in the DT than DS cultivars. Carbohydrates have been documented to affect ABA - dependent metabolic pathways, crucial for drought modulation in plants (Zhang et al., 2006). In addition, carbohydrates also affect the biosynthesis of other metabolites that generate energy, alter gene expression regulation and signal transduction (Hoekstra et al., 2001). The accumulation of sugars in this study was accompanied by an increase in the concentrations of the organic acid citrate, though there was no statistically significant difference $(p>0.74)$ between the DT and DS cultivars. An increase in citrate leads to an increase in other Krebs cycle metabolites. This is supported by a study which showed how fluoroacetate initially increased citrate levels without significantly increasing the levels of the other substrates. When citrate levels increased up to three fold, a significant increase in the levels of the other Krebs cycle intermediates occurred (Goldberg et al., 1966). This result obtained in our study also corroborates the result by Vasquez-Robinet et al., (2008) who documented higher levels of Krebs cycle intermediates in DT Sullu variety as compared to the DS Negra Ojosa variety.

\section{Flavonoid metabolism}

Vanillic acid, protocatechuic acid, gallic acid, caffeic acid and trans-cinnamic acid were significantly $(\mathrm{p}>0.05)$ higher in the DT compared to the DS cultivars after five-hour wither. Coumaric acid had a lower abundance in DT compared with DS cultivars after five-hour wither (Figure 8). These results indicate that the DT cultivars use flavonoids at a higher rate than DS, which enables them to cope with drought stress. Many plants use phenylpropanoids to respond to and mitigate stress through the shikimate pathway, which produces phenylalanine (Tounekti et al., 2013). 


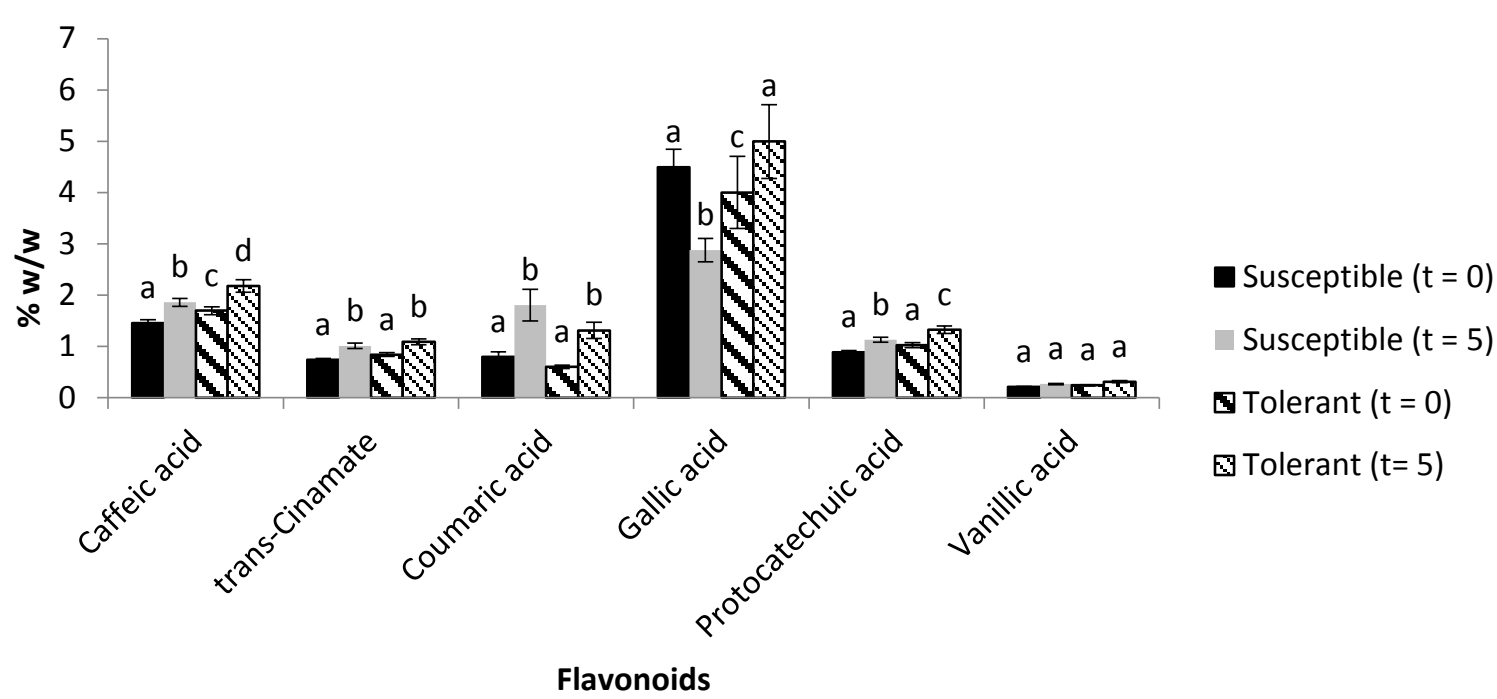

Figure 8: Differences in flavonoid abundances between DT and DS at $t=0$ and $t=5$. The means are based on five independent growing plants of two DT or two DS cultivars. Error bars are representative of S.E.M with $n=$ 5 .

The levels of phenylalanine (Figure 6) obtained in this study showed no statistically significant difference $(\mathrm{p}=0.08)$ between DT and DS cultivars. Although not significantly different, the levels were higher in the DT cultivars and this in turn resulted in a subsequent rise in the levels of caffeic acid that was significantly different between the DT and DS cultivars, also conferring drought tolerance on the Dt cultivars. This is in agreement with results obtained in a study where higher concentrations of caffeoylquinic acid and phenylalanine were detected in DT species while cinnamic acid and quercetin were higher in the DS species (Lugan et al., 2009). Coumaric acid levels were lower in DT than in DS cultivars. This correlates with the results obtained in a study by $\mathrm{Hu}$ et al. (1999) where coumaric acid levels significantly increased in the xylem sap of DS maize plants over a 12 day period. Coumaric acid was identified as an intermediate in lignin biosynthesis in water stressed maize, which explains an increase in coumaric acid (Hu et al., 1999) to prevent water loss. The increase in amino acids content i.e. phenylalanine, triggers the biosynthesis of phenolic acids through the cinnamic acid pathway. This results in lignin synthesis. Gallic acid, caffeic acid and trans-cinnamic acid were higher in the DT cultivars (Figure 8) and this is due to an increase in amino acids biosynthesis due to drought stress.

The above metabolite results confirm that the five-hour withering of tea leaves has similar metabolite modulation patterns as seen in other plant species over longer times 5-12 days growing in soil (Engelbrecht and Kursar, 2003). This may be due to the absence of roots in the tea shoots that cause the metabolites to change in a short time. Thus we believe that the SWAPDT method may be a valid method for predicting drought tolerance in tea. 


\section{Total polyphenol content}

In the current study, it was shown that both sPC105 and sPC165 had higher total polyphenol content (TPC) than the tPC153 and tPC168 cultivars, Figure 9. This was the expected result because water is one of the raw materials used in photosynthesis; its lack thereof would have a negative impact on the synthesis of primary and secondary metabolites. This could also be because of several mechanisms for modulating drought by DT cultivars. Polyphenols have antioxidant properties which play a key role in scavenging free radicals produced under stress conditions in plants (Lien et al., 1999). As a result DS cultivars depend on both high concentrations of carbohydrates such as fructose, and high TPC to compensate for the lack of other stress combating mechanisms. A study on the flavonoid content demonstrated that a tea variety with higher TPC was more tolerant to both light and water stress unlike the susceptible varieties with lower flavonoid levels (Yaginuma et al., 2003). This differs from our results. The variation of TPC obtained in the reported study however coincides with results in a study aimed at analysing the influence of shade on flavonoid biosynthesis in relation to flavonoid pathway gene expression in tea leaves. Shade notably reduces flavonoid concentration (catechins and $O$-glycosylated flavonols) in tea leaves, with $O$-glycosylated flavonols compounds decreasing up to $43.26 \%$ in shade grown tea plants compared to field grown plants (Wang et al., 2012), explaining why PC153 has a low TPC. There is however

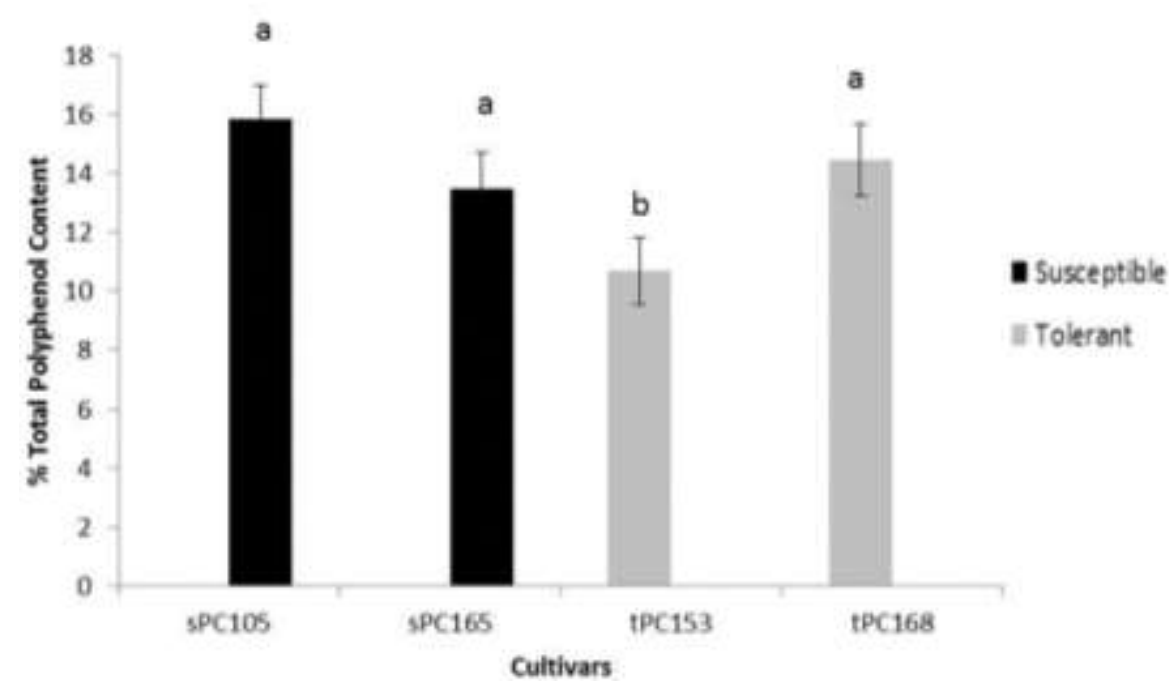

Figure 9: Differences in \%TPC abundances between DT (tPC153 and tPC168) and DS (sPC105 and sPC165). The means are based on five independent growing plants of two DT or two DS cultivars. Error bars are representative of SEM with $\mathrm{n}=5$. 
no explanation as to why PC168 did not drop in TPC as this particular cultivar has been classified as tolerant from field studies over several years (Mphangwe et al., 2013). Although these studies serve to further confirm that TPC can be used as an indicator for drought tolerance in C. sinensis (Cheruiyot et al., 2007), it must be noted that TPC cannot be used to classify tea cultivars for drought tolerance when the plants are grown under shade, as shade has been documented to influence flavonoid biosynthesis. Thus, TPC is considered unreliable because we need to assess new cultivars at an early stage, while they are growing in the nursery, under shade.

RWC

A logistic regression plot (Figure 10) was created from the RWC data obtained at the five hour mark for each sample in the SWAPDT method for known DT and DS cultivars. This plot separates the DT from the DS cultivars. The plot shows that after five-hour wither in the SWAPDT method, the DT cultivars have > 57\% RWC. Only three of the 20 plants were misclassified, based on this $57 \%$ threshold value. From this plot, logistics probability formulas were generated as shown below:

$$
P(\text { tolerant })=1 /[1+\operatorname{Exp}(\text { Lin }[\text { Susceptible }])]
$$

where Lin [Susceptible] $=30.451-0.530 * \mathrm{RWC}$ at five hours. Using this formula, the \% RWC after five-hour withering, can be used to calculate a new cultivars probability for DT. The cultivars with P (tolerant) $>0.5$ can be classified as DT. The closer P (tolerant) is to 1 , the higher the probability that the cultivar will be DT. The probability of drought tolerance will be higher than $90 \%$, when the RWC $>62 \%$ in the SWAPDT method. This method is objective, reproducible and practical because it is based only on a mass balance and a drying oven set at $37^{\circ} \mathrm{C}$. 


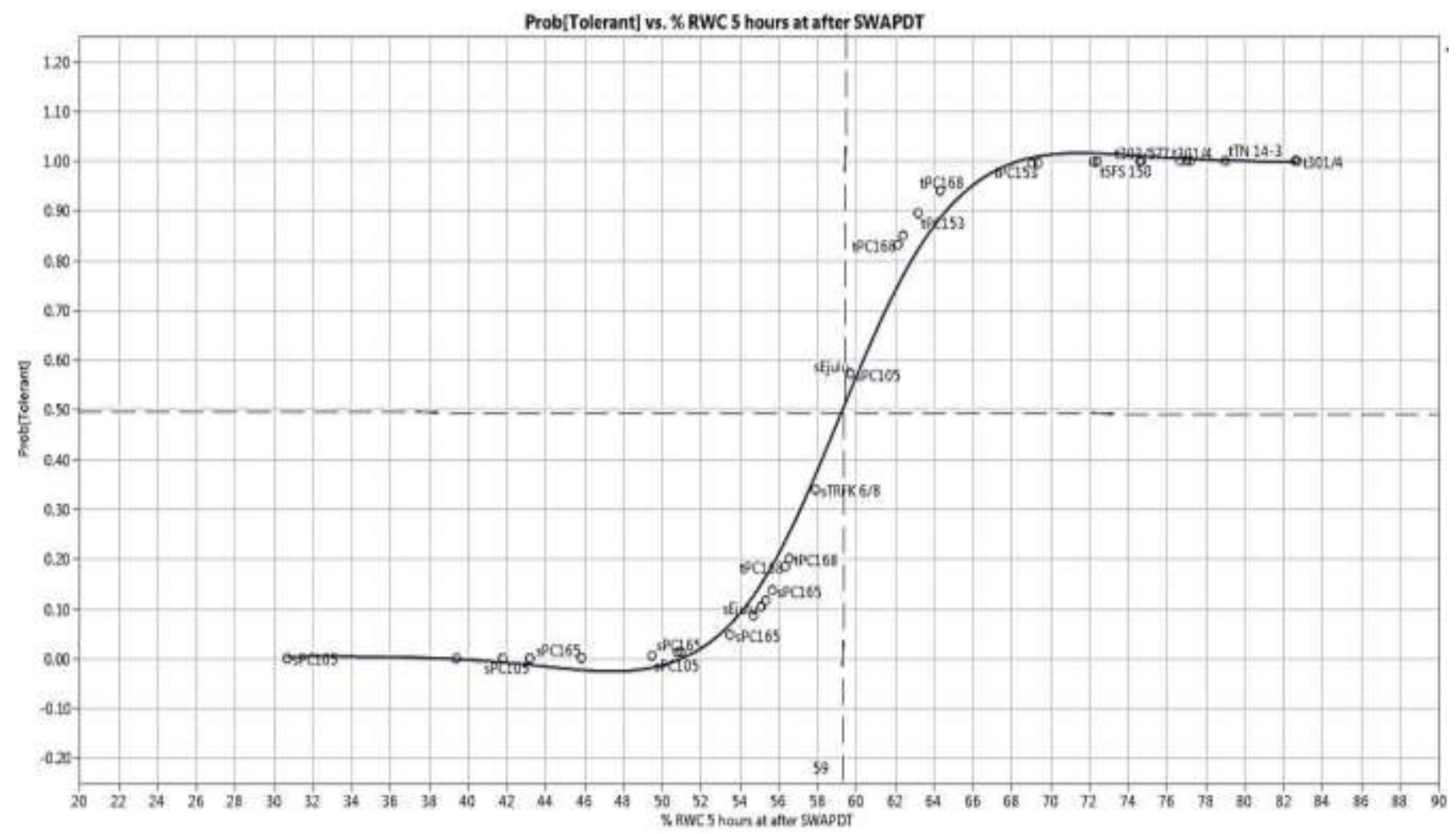

Figure 10: Logistic regression cumulative fit probability for drought tolerance versus \%RWC after SWAPDT.

\section{Conclusion}

An inexpensive and practical method, named SWAPDT, has been developed for predicting the drought tolerance of tea cultivars. The metabolite changes for amino acids, flavonoids and sugars, were similar in this five-hour withering in plucked tea shoots, as found in other plant species with whole plants growing in pots or in the field over longer periods of drought (Cramer et al., 2007). This method relies only on the \%RWC of tea leaves after the five-hour withering method. The metabolite profiles obtained from this study show that DT tea cultivars differ from DS tea cultivars. The metabolomes indicate that the DT and DS cultivars have an accumulation of either primary sugar, amino acid or citric acid metabolites. There is a significant variation in metabolite content (amino acid, sugars) in DT and DS tea cultivars between $\mathrm{t}=0$ and $\mathrm{t}=5$. The resultant variation in $\% \mathrm{RWC}$ observed in each of the cultivars provides a basis for the selection, improvement and management of the cultivars to ensure better yields and quality. Although the metabolomes are variable among DT and DS cultivars, further studies into the relationship amongst metabolites showed some metabolites had a high degree of similarity in their abundance profiles in DT and DS tea cultivars. Several metabolites with significant differences in accumulation under drought-like conditions in both DT and DS tea cultivars exhibited intraspecific variation in metabolite 
accumulation. The results presented herein demonstrate that future experiments aimed at the comprehension of the complexities of drought stress responses in tea plant must take into consideration the intraspecific variation in genotypes. The SWAPDT method provides a basis for selection of new drought tolerant tea cultivars that may lead to improvement of crop productivity, amidst challenges imposed by drought due to climate change.

\section{Acknowledgements}

The authors acknowledge the financial support to conduct this research, and study grants for CN and RK from James Finlay (Kenya) Ltd, George Williamson (Kenya) Ltd, Sotik Tea Company (Kenya) Ltd, Mcleod Russell (Uganda) Ltd, and the Tea Research Institute of Kenya. The $C$. sinensis cultivars used in this study were provided by the Tea Research Foundation of Central Africa (Malawi) and the Tea Research Institute of Kenya. Supplementary funding was provided by, the Technology and Human Resources for Industry Programme (THRIP), an initiative of the Department of Trade and Industries of South Africa (dti), the National Research Foundation (NRF) of South Africa, and the University of Pretoria (South Africa).

\section{References}

ABEBE, T., GUENZI, A. C., MARTIN, B. \& CUSHMAN, J. C. 2003. Tolerance of mannitol-accumulating transgenic wheat to water stress and salinity. Plant physiology, 131, 1748-1755.

ARBONA, V., MANZI, M., OLLAS, C. D. \& GÓMEZ-CADENAS, A. 2013. Metabolomics as a tool to investigate abiotic stress tolerance in plants. International journal of molecular sciences, 14, 4885-4911.

AYAZ, F., KADIOGLU, A. \& TURGUT, R. 2000. Water stress effects on the content of low molecular weight carbohydrates and phenolic acids in Ctenanthe setosa (Rosc.) Eichler. Canadian Journal of Plant Science, 80, 373-378.

CHERUIYOT, E. K., MUMERA, L. M., NG'ETICH, W. K., HASSANALI, A. \& WACHIRA, F. 2007. Polyphenols as potential indicators for drought tolerance in tea (Camellia sinensis L.). Bioscience, biotechnology, and biochemistry, 71, 2190-2197.

CRAMER, G. R., ERGÜL, A., GRIMPLET, J., TILLETT, R. L., TATTERSALL, E. A., BOHLMAN, M. C., VINCENT, D., SONDEREGGER, J., EVANS, J. \& OSBORNE, C. 2007. Water and salinity stress in grapevines: early and late changes in transcript and metabolite profiles. Functional \& integrative genomics, 7, 111-134.

DELAUNEY, A. J. \& VERMA, D. P. S. 1993. Proline biosynthesis and osmoregulation in plants. The plant journal, 4, 215-223.

ENGELBRECHT, B. M. \& KURSAR, T. A. 2003. Comparative drought-resistance of seedlings of 28 species of co-occurring tropical woody plants. Oecologia, 136, 383393. 
FARRANT, J. M., LEHNER, A., COOPER, K. \& WISWEDEL, S. 2009. Desiccation tolerance in the vegetative tissues of the fern Mohria caffrorum is seasonally regulated. The Plant Journal, 57, 65-79.

GOLDBERG, N. D., PASSONNEAU, J. V. \& LOWRY, O. H. 1966. Effects of changes in brain metabolism on the levels of citric acid cycle intermediates. Journal of Biological Chemistry, 241, 3997-4003.

HAMANISHI, E. T., BARCHET, G. L., DAUWE, R., MANSFIELD, S. D. \& CAMPBELL, M. M. 2015. Poplar trees reconfigure the transcriptome and metabolome in response to drought in a genotype-and time-of-day-dependent manner. BMC genomics, 16, 329.

HARE, P. \& CRESS, W. 1997. Metabolic implications of stress-induced proline accumulation in plants. Plant growth regulation, 21, 79-102.

HÄUSLER, R. E., LUDEWIG, F. \& KRUEGER, S. 2014. Amino acids-A life between metabolism and signaling. Plant Science, 229, 225-237.

HELENO, S. A., MARTINS, A., QUEIROZ, M. J. R. \& FERREIRA, I. C. 2015. Bioactivity of phenolic acids: Metabolites versus parent compounds: A review. Food chemistry, 173, 501-513.

HOEKSTRA, F. A., GOLOVINA, E. A. \& BUITINK, J. 2001. Mechanisms of plant desiccation tolerance. Trends in plant science, 6, 431-438.

HU, W.-J., HARDING, S. A., LUNG, J., POPKO, J. L., RALPH, J., STOKKE, D. D., TSAI, C.-J. \& CHIANG, V. L. 1999. Repression of lignin biosynthesis promotes cellulose accumulation and growth in transgenic trees. Nature biotechnology, 17, 808-812.

IGLESIAS, D. J., LLISO, I., TADEO, F. R. \& TALON, M. 2002. Regulation of photosynthesis through source: sink imbalance in citrus is mediated by carbohydrate content in leaves. Physiologia Plantarum, 116, 563-572.

IORDACHESCU, M. \& IMAI, R. 2008. Trehalose biosynthesis in response to abiotic stresses. Journal of integrative plant biology, 50, 1223-1229.

JANSKÁ, A., MARŠÍK, P., ZELENKOVÁ, S. \& OVESNA, J. 2010. Cold stress and acclimation-what is important for metabolic adjustment? Plant Biology, 12, 395-405.

KAPLAN, F. \& GUY, C. L. 2004. $\beta$-Amylase induction and the protective role of maltose during temperature shock. Plant Physiology, 135, 1674-1684.

KERCHEV, P. I., FENTON, B., FOYER, C. H. \& HANCOCK, R. D. 2012. Plant responses to insect herbivory: interactions between photosynthesis, reactive oxygen species and hormonal signalling pathways. Plant, cell \& environment, 35, 441-453.

KUSAKA, M., OHTA, M. \& FUJIMURA, T. 2005. Contribution of inorganic components to osmotic adjustment and leaf folding for drought tolerance in pearl millet. Physiologia Plantarum, 125, 474-489.

LIEN, E. J., REN, S., BUI, H.-H. \& WANG, R. 1999. Quantitative structure-activity relationship analysis of phenolic antioxidants. Free Radical Biology and Medicine, 26, 285-294.

LUGAN, R., NIOGRET, M. F., KERVAZO, L., LARHER, F. R., KOPKA, J. \& BOUCHEREAU, A. 2009. Metabolome and water status phenotyping of Arabidopsis under abiotic stress cues reveals new insight into ESK1 function. Plant, cell \& environment, 32, 95-108.

MPHANGWE, N. I., VORSTER, J., STEYN, J. M., NYIRENDA, H. E., TAYLOR, N. J. \& APOSTOLIDES, Z. 2013. Screening of tea (Camellia sinensis) for trait-associated molecular markers. Applied biochemistry and biotechnology, 171, 437-449.

NISHIZAWA, A., YABUTA, Y. \& SHIGEOKA, S. 2008. Galactinol and raffinose constitute a novel function to protect plants from oxidative damage. Plant physiology, 147, 1251-1263. 
OGBAGA, C. C., STEPIEN, P. \& JOHNSON, G. N. 2014. Sorghum (Sorghum bicolor) varieties adopt strongly contrasting strategies in response to drought. Physiologia plantarum, 152, 389-401.

PANDEY, R., AGARWAL, R., JEEVARATNAM, K. \& SHARMA, G. 2004. Osmotic stress-induced alterations in rice (Oryza sativa L.) and recovery on stress release. Plant Growth Regulation, 42, 79-87.

PAVLI, O. I., VLACHOS, C. E., KALLONIATI, C., FLEMETAKIS, E. \& SKARACIS, G. N. 2013. Metabolite profiling reveals the effect of drought on sorghum ('Sorghum bicolor'L. Moench) metabolism. Plant Omics, 6, 371.

RIZHSKY, L., LIANG, H., SHUMAN, J., SHULAEV, V., DAVLETOVA, S. \& MITTLER, R. 2004. When defense pathways collide. The response of Arabidopsis to a combination of drought and heat stress. Plant physiology, 134, 1683-1696.

RODRIGUES, M., CHAVES, M., WENDLER, R., DAVID, M., QUICK, W., LEEGOOD, R., STITT, M. \& PEREIRA, J. 1993. Osmotic adjustment in water stressed grapevine leaves in relation to carbon assimilation. Functional Plant Biology, 20, 309-321.

ROLLAND, F., BAENA-GONZALEZ, E. \& SHEEN, J. 2006. Sugar sensing and signaling in plants: conserved and novel mechanisms. Annu. Rev. Plant Biol., 57, 675-709.

RONTEIN, D., DIEUAIDE-NOUBHANI, M., DUFOURC, E. J., RAYMOND, P. \& ROLIN, D. 2002. The metabolic architecture of plant cells stability of central metabolism and flexibility of anabolic pathways during the growth cycle of tomato cells. Journal of Biological Chemistry, 277, 43948-43960.

RUAN, C.-J. \& TEIXEIRA DA SILVA, J. A. 2011. Metabolomics: creating new potentials for unraveling the mechanisms in response to salt and drought stress and for the biotechnological improvement of xero-halophytes. Critical reviews in biotechnology, 31, 153-169.

SAKURAI, M., FURUKI, T., AKAO, K.-I., TANAKA, D., NAKAHARA, Y., KIKAWADA, T., WATANABE, M. \& OKUDA, T. 2008. Vitrification is essential for anhydrobiosis in an African chironomid, Polypedilum vanderplanki. Proceedings of the National Academy of Sciences, 105, 5093-5098.

SIRCELJ, H., TAUSZ, M., GRILL, D. \& BATIC, F. 2005. Biochemical responses in leaves of two apple tree cultivars subjected to progressing drought. J Plant Physiol, 162, 1308-18.

SLAMA, I., ABDELLY, C., BOUCHEREAU, A., FLOWERS, T. \& SAVOURÉ, A. 2015. Diversity, distribution and roles of osmoprotective compounds accumulated in halophytes under abiotic stress. Annals of botany, mcu239.

TONG, X., TAYLOR, A. W., GILES, L., WITTERT, G. A. \& SHI, Z. 2014. Tea consumption is inversely related to 5-year blood pressure change among adults in Jiangsu, China: a cross-sectional study. Nutrition journal, 13, 98.

TOUNEKTI, T., JOUBERT, E., HERNÁNDEZ, I. \& MUNNÉ-BOSCH, S. 2013. Improving the polyphenol content of tea. Critical Reviews in Plant Sciences, 32, 192-215.

URANO, K., MARUYAMA, K., OGATA, Y., MORISHITA, Y., TAKEDA, M., SAKURAI, N., SUZUKI, H., SAITO, K., SHIBATA, D. \& KOBAYASHI, M. 2009. Characterization of the ABA-regulated global responses to dehydration in Arabidopsis by metabolomics. The Plant Journal, 57, 1065-1078.

WANG, Y., GAO, L., SHAN, Y., LIU, Y., TIAN, Y. \& XIA, T. 2012. Influence of shade on flavonoid biosynthesis in tea (Camellia sinensis (L.) O. Kuntze). Scientia horticulturae, 141, 7-16.

WECKWERTH, W., WENZEL, K. \& FIEHN, O. 2004. Process for the integrated extraction, identification and quantification of metabolites, proteins and RNA to reveal their coregulation in biochemical networks. Proteomics, 4, 78-83. 
YAGINUMA, S., SHIRAISHI, T. \& IGARASHI, K. 2003. Developmental transition of the flavonoid contents in safflower leaves during stress-loaded cultivation. Bioscience, biotechnology, and biochemistry, 67, 1691-1698.

YOSHIDA, T. \& SAKAMOTO, T. 2009. Water-stress induced trehalose accumulation and control of trehalase in the cyanobacterium Nostoc punctiforme IAM M-15. The Journal of general and applied microbiology, 55, 135-145.

ZHANG, J., JIA, W., YANG, J. \& ISMAIL, A. M. 2006. Role of ABA in integrating plant responses to drought and salt stresses. Field Crops Research, 97, 111-119. 